\title{
Textualidades contemporâneas: tendências e estilos da narrativa latino-americana*
}

Fecha de recepción: 23 de noviembre de 2017

Fecha de aprobación: 21 de abril de 2018

\section{Resumen}

El presente artículo de revisión tiene por finalidad establecer una serie de reflexiones sobre las relaciones de la literatura latinoamericana con la estética contemporánea para pensar en qué medida la especificidad del lenguaje artístico redimensiona el estatuto ficcional y su potencial crítico. Considera también perspectivas innovadoras que escapan al relato canónico y a la categorización genérica tradicional al imponer nuevas expresiones estéticas y temáticas en las que la experiencia del desplazamiento, textual y / o físico, está presente. Con este estudio se quiere explorar un corpus de narrativas contemporáneas cuyas prácticas creativas y procedimientos discursivos operan en la frontera de los géneros, de los lenguajes y de las formas de expresión.

Palabras Clave: narrativa latinoamericana; tendencias y estilos; estética contemporánea; hibridismo; desplazamiento.

Citar: Pérez Montañés, A. (enero-junio de 2018). Textualidades contemporâneas: tendências e estilos da narrativa latino-americana. La Palabra,(32), 43-63. doi: https://doi.org/10.19053/01218530.n32.2018.8162.

\section{Amanda Pérez Montañés}

Doutora em Ciências Humanas da Universidade Federal de Santa Catarina (UFSC/Brasil). Professora Associada; docente do Curso de Letras-Espanhol do Departamento de Letras Estrangeiras Modernas/Centro de Letras e Ciências Humanas da Universidade Estadual de Londrina (LEM/CLCH/UEL). amandapm34@hotmail.com

* Artigo de revisão, produto de um estudo preliminar para a elaboração do projeto de pesquisa: "Textualidades contemporâneas: hibridismos e deslocamentos nas novas tendências e estilos da narrativa latino-americana (1990-2015)", aprovado em novembro de 2016, sobre minha orientação, a ser desenvolvido no período de 08/12/2016 a 07/12/2019. 


\section{la palabra}

\section{Contemporary Textualities: Tendencies and Styles in Latin American Narrative}

\section{Abstract}

This review article establishes a series of reflections on the relations between Latin American literature and contemporary aesthetics, and the ways in which the specific artistic languages redimension the fictional statute and its critical potential. It also considers innovative perspectives that escape canonical narrative and traditional genre categorization by imposing new aesthetic expressions and themes in which the experience of textual or physical displacement is present. This paper explores a corpus of contemporary narrative works whose creative practices and discursive procedures operate on the frontier of genre, languages and forms of expression.

Key words: Latin American narrative; Tendencies and styles; Contemporary aesthetics; Hybridity; Displacement.

\section{Textualités contemporaines: tendences et styles des récits latino-américains.}

\section{Résumé}

Dans cet article nous réfléchirons sur les rapports de la litérature latinoaméricaine avec l'esthétique contemporaine pour nous demander dans quelle mesure la spécicifité du langage artistique redéfinit le statut fictionel et son potentiel critique. Nous considérons des perspectives innovatrices qui se soustraient au récit canonique et à la catégorisation générique traditionelle, ainsi que de nouvelles expressions estéthiques et tématiques dans lesquelles l'expérience du déplacement textuel et / ou physique est présent. Dans cet article nous voulons étudier un corpus de récits contemporains qui opèrent à la frontière des genres, des langages et des formes d'expression à partir de leurs pratiques de création et de leurs formes d'expresssion.

Mots clés: récits latino-américains; tendences et styles; estéthique contemporaine; hybridité; déplacement. 
Ser contemporáneo es mucho más que un ciego abrazo del presente Terry Smith

A forma de considerar e analisar a literatura encontrase estreitamente relacionada às concepções estéticas que determinam a seleção, ordenamento e a interpretação do corpus literário, também regem as modalidades da significação e o efeito estético; por meio delas é estabelecido o que ler e como ler. Entretanto, esses pressupostos estéticos não são homogêneos, constituem um campo problemático e contraditório, centro da atividade teórica e crítica (Perus, 1983). Segundo os objetivos deste estudo, convém perguntar até onde os desenvolvimentos teóricos e suas modalidades de leitura têm dado conta, por exemplo, das particularidades da literatura latino-americana atual, de suas transformações e das novas potencialidades estéticas? A pergunta pressupõe a irredutibilidade da escrita a concepções universais do espírito ou da língua, embora, possam conduzir a reflexão à pertinência ou não de uma teoria literária latinoamericana, mesmo que, como julgaram alguns, a literatura da América Latina ainda careça de uma crítica acorde com suas especificidades, sem contribuições substanciais à literatura mundial (Bueno, 1991). No entanto, se considerarmos que toda teoria deve ser adaptada ao objeto concreto do qual ela pretende dar conta, por essa mesma razão, é um processo em que se pode partir de conceituações existentes se quisermos transformá-las, contribuindo para o desenvolvimento crítico.

É justamente nesse eixo analítico que o presente artigo objetiva estabelecer uma série de reflexões sobre as relações da literatura da América Latina com a estética contemporânea para pensar em que medida a especificidade da linguagem artística redimensiona o estatuto ficcional e o seu potencial crítico ao abordar perspectivas inovadoras que escapam ao relato canônico e à categorização genérica tradicional impondo novas expressões estéticas e temáticas em que a vivência de deslocamento, textual e/ou físico, entre outras, encontrase presente. Com este estudo, num recorte parcial, pretende- se explorar um corpus $^{1}$ de textualidades contemporâneas cujas práticas criativas $\mathrm{e}$ procedimentos discursivos operam na fronteira dos gêneros, das linguagens e das formas expressivas.

\section{A tradição da ruptura}

A partir das premissas anteriores, pode-se afirmar, à maneira de hipótese, que nos anos 1960 uma série de rupturas começou a ser produzida na literatura da América Latina modificando profundamente a sua estrutura e o seu funcionamento, e, portanto, as formas de expressão e o estatuto crítico dessa literatura que não respondem mais às tendências da tradição anterior. Rupturas resultantes de um processo duplo: por um lado, referem-se às novas modalidades da escrita e, por outro, correspondem ao desenvolvimento da teoria literária dentro e fora dela (Rama, 1982).

Na América Latina, as décadas de 1960 e 1970 foram de maior densidade cultural. A esse período correspondeu o

O critério assumido, com respeito às obras aqui comentadas ou citadas, é cronológico: obras publicadas a partir de 1960 Para tanto, adoptou-se o método da amostragem no que diz respeito à seleção de obras e autores. 
boom $^{2}$ da literatura e da cultura latino-americana, impulsor da radicalização da arte literária neste continente, ao instaurar a tradição da ruptura com respeito ao cânone em vigor na época. Circulavam entre os artistas e os estudiosos diversas publicações numa extensa rede de intercâmbio intelectual, permitindo o diálogo e a conscientização para a reconstrução de novos paradigmas literários, como afirma Mora Valcárcel (1985), são representados por uma “[...] transformação e renovação das técnicas e recursos narrativos, ajustados à nova temática"3 (p. 45). É possível advertir, então, na literatura latinoamericana deste período, uma clara tendência a maiores autonomização e especialização do discurso literário, apropriando-se do material simbólico e discursivo de diversas fontes, populares e/ou cultas, que aportam destacadas formas de renovação literária, teórica e crítica.

O boom ocorreu na década de 1960, com algumas manifestações importantes na década de $1950^{4}$. A preocupação com a forma não se tornou uma obsessão estética - como nas correntes esteticistas dos movimentos de vanguarda do início do século XX até a década de $1940^{5}$ - e sim em uma atitude política, assumida conscientemente, baseada na premissa de que para expressar uma visão revolucionária do mundo é necessário revolucionar os meios de expressão dessa visão, ou seja, a revolução estética deve começar no interior da própria obra, em sua forma de expressão, como afirma Julio Cortázar no capítulo 99 de Rayuela ${ }^{6}$ (1963): "[...] não se pode denunciar o que quer que seja se a denúncia for feita dentro do sistema a que pertence o denunciado. Escrever contra o capitalismo com a bagagem mental e o vocabulário que derivam do capitalismo é perder tempo" (Cortázar, 2011, p. 508).

Na nova narrativa, a arma do escritor é a linguagem, pois só renovando a linguagem podese renovar o mundo. A fusão do estético e do político, executada sobretudo a partir da inovação da linguagem, concede à literatura desse período seu caráter de síntese, em que a imaginação, em vez de se opor ao realismo, constitui a condição essencial de um realismo mais vital. O realismo mágico, o real maravilhoso, o realismo fantástico ou neofantástico,

2 O escritor chileno Luis Harss, no livro Los nuestros (1966), denominou pela primeira vez com o nome de "boom" o novo cânone da literatura latino-americana dos anos 1960, cuja explosão editorial atingiu seu auge em 1967 com a publicação de Cien años de soledad de Gabriel García Márquez. No entanto, alguns críticos (como Ayén Xavi, entre outros) consideram 1963 o ano de início do movimento, com a publicação de La ciudad y los perros, de Mario Vargas Llosa. Para Carmen Galindo (1978), retomando José Donoso, o fundador do boom seria Carlos Fuentes que publicou em 1958 o romance La región más transparente, obra inovadora pela ruptura das formas tradicionais da narrativa e a exploração pioneira da linguagem. Em Aquellos años del boom (2013), Ayén Xavi faz uma biografia grupal em que narra em detalhe o auge da literatura latino-americana desse momento, elaborando uma crônica do fenômeno social que foi propiciado, em parte, pelo engajamento comercial da agente literária Carmen Balcells.

3 As traduções das citações são da autora, exceto quando indicado de outro modo.

4 El sueño de los héroes (1954), de Adolfo Bioy Casares; Pedro Páramo (1955), de Juan Rulfo; Grande Sertão Veredas (1956), de João Guimarães Rosa; La región más transparente (1958), de Carlos Fuentes; Los ríos profundos (1959), de José María Arguedas, são obras dos anos 1950 que anteciparam o boom e se caracterizaram em seus aspectos formais por inovações linguísticas e temáticas, quebra da unidade narrativa, entrelaçamento ou fragmentação de histórias, uso e valorização de um léxico regional ou invenção de palavras para fins expressivos.

5 Na vanguarda literária latino-americana destacam-se importantes movimentos: o Creacionismo de Vicente Huidobro, o Ultraismo de Jorge Luis Borges, o Estridentismo de Manuel Maples Arce, o Modernismo brasileiro de Mario de Andrade e Oswald de Andrade, ou a experimentação criativa nas expressões poéticas de Oliveiro Girondo, Cesar Vallejo, Pablo Neruda, entre outros.

6 Na tradução em português: O Jogo da amarelinha (2011). 
o realismo maravilhoso, e o "realismo visceral", são algumas das novas vertentes do fantástico latino-americano em que a realidade objetiva coexiste com o sonho e a fantasia, o compromisso político ou social se une à consciência estética, e os conflitos regionais fundem-se com outros de ordem existencial, configurando, em última instância, a realidade cultural da América Latina (Horne, 2011). A fusão de elementos diversos e aparentemente opostos, míticos e reais, é a essência da nova ficção, que permite expressar de maneira profunda e integral a relatividade da existência humana e a crise de nosso tempo. Dessa forma, o efeito mais marcante do boom "[...] consistiu em chamar a atenção para a originalidade e o vigor de uma literatura considerada até então periférica, mero reflexo retardatário das literaturas centrais" (Cárcamo, 1990, p. 239).
Um número significativo de intelectuais e autores pertence a esse fértil período ${ }^{8}$, no entanto, as ditaduras no Cone Sul da América nas décadas de 1960 e 1970 interromperam a criação artística, houve uma fratura no campo intelectual, sendo que, “[...] para aqueles que permaneceram em seus países, $o$ problema mais imediato tornouse o da censura; e para os que se exilaram, a distância do país de origem. Para uns e outros, foi radical a mudança nos rumos estéticos e políticos" (Vidal, 2004, p. 19). A preocupação já não é mais conceber uma literatura latino-americana "revolucionária" (enquanto renovação da linguagem e das formas expressivas), mas qual será a estratégia que deve ser empregada para resistir à censura e à repressão. Nasce nos intelectuais a exigência de um engajamento crítico no desenvolvimento políticosocial e cultural da América Latina9.
No Cone Sul, a repressão do regime ditatorial determinou o surgimento de uma literatura de resistência que buscou denunciar e combater as ditaduras, confrontando-se com o problema de como narrar o horror (Schøllhammer, 2004). Mesmo nesse contexto, algumas das figuras mais destacadas continuaram criando, escrevendo e publicando em seus países ou no exílio. ${ }^{10}$ Em Cuba, a fundação Casa de las Américas, instituição dirigida por Roberto Fernández Retamar e Haydeé Santamaría, contribuiu também para a preservação da atividade criativa do continente, permitindo assim o intercâmbio cultural mediante a publicação de periódicos e a organização de festivais e de concursos literários com a presença de destacados intelectuais da América Latina e da Europa.

Além do sucesso de vendas e do êxito editorial, a produção literária dos anos 1960 deixou

\footnotetext{
$7 \quad$ Categoria proposta por Roberto Bolaños, em Los detectives salvajes (1999). Embora pouco ilumine o registro de sua estética, permite explorar e discutir algumas das tendências literárias hegemônicas na América Latina (leia-se, realismo mágico e real maravilhoso) nas décadas de 1960 e 1970. Segundo Paula Aguilar (2013), à imagem mágica ou maravilhosa de nosso continente, Bolaños contrapõe o "realismo visceral" ou "real visceralismo", termo que alude aos órgãos do corpo ou às entranhas da barbárie, cuja violência tem deixado profundas feridas. O realismo visceral "permite oscilar entre uma história que enfraquece as certezas do 'real' e um discurso fortemente referencial" (Aguilar, 2013, p.299).

8 Algumas obras ilustram a revolução literária desse período: Hijo de hombre (1960) e Yo el supremo (1974), de Augusto Roa Bastos; Rayuela (1963) e 62: Modelo para armar (1968), de Julio Cortázar; La ciudad y los perros (1964), La casa verde (1966) e Conversación en la catedral (1968), de Mario Vargas Llosa; Paradiso (1966), de José Lezama Lima; Cien años de soledad (1967), de García Márquez, entre outras.

9 As polêmicas sobre o engajamento político que os intelectuais deviam adotar marcaram o clima político e cultural deste período. Dos confrontos diretos mais exacerbados entre intelectuais da época pode-se citar a famosa polêmica de Julio Cortázar, Oscar Collazos e Mario Vargas Llosa, em torno da publicação no semanário "Marcha" (Montevidéu, nas edições de 30 de agosto e 5 de setembro de 1969, a pedido de Ángel Rama) do ensaio de Collazos: La encrucijada del lenguaje. A polêmica permaneceu viva durante alguns anos graças à publicação em Siglo XXI de sucessivas edições do livro Literatura en la revolución y revolución en la literatura (Collazos; Cortázar; Vargas Llosa, 1970) em que estão incluídos de forma completa o ensaio de Collazos e as respostas de Cortázar, Vargas Llosa e Collazos. A respeito ver: Pérez Montañés, 2013.

10 Julio Cortázar, Eduardo Galeano, Manuel Puig, Mario Benedetti, Augusto Roa Bastos, entre outros autores, desenvolveram boa parte de suas obras no exílio.
} 
marcas profundas na literatura posterior. Passadas mais de cinco décadas do boom, fezse necessário estabelecer distinções entre a produção desse período e a atual literatura latino-americana, que alguns críticos costumam denominar narrativa do pós-boom. ${ }^{11}$ Para Silvia Inés Cárcamo (1990, p.239),

[...] os escritores mais jovens - aqueles que apenas começavam a publicar no final da década de 60 ou aqueles que escreviam a suas obras fundamentais, nos dois lustros seguintes - sentem já a urgência de diferenciar a sua obra da anterior, preocupados talvez, e com justa causa, com os estereótipos da críti$\mathrm{ca}$, que tende a reduzir toda a literatura continental da atualidade a dois ou três modelos que são, exatamente, os que se ajustam à poética dos anos 60.

$\mathrm{Na}$ narrativa latino-americana contemporânea, o realismo mágico de Gabriel García Márquez, o fantástico borgiano, o neofantástico de Julio Cortázar ou o onírico de Juan Rulfo já foram deixados para atrás como modelos a serem seguidos pelos narradores atuais (Horne, 2011). Agora, trata-se de pensar, entre outras possibilidades, a literatura latino-americana a partir do conceito de fronteira como eixo articulador de proposições em torno de entrecruzamentos e/ou deslocamentos formais e temáticos, cuja reflexão deve ser marcada pela "contemporaneidade" das novas tendências e estilos; e as possibilidades de reconfiguração das tendências passadas, como forma de inovação útil para pensar novas formas de expressão e representação ${ }^{12}$.

Um olhar retrospectivo sobre a trajetória da narrativa atual na América Latina permite realizar uma revisão, mesmo que sucinta, de alguns dos momentos relevantes ao longo das últimas décadas do século XX. Para tanto, e à guisa de exemplo, centram-se as reflexões na Argentina, um dos polos culturais mais destacados do continente, onde o período de preparação dos escritores da chamada "geração de 70" ou do pós-boom coincide com um momento de alta experimentação criativa, que determinou as bases para a definição das novas tendências do presente, estabelecidas, em parte, a partir da década de 1960, como já dito. Segundo Ricardo Piglia (1986, p. 61), "[...] os anos 60, mais do que uma época, representam uma posição definida pela circulação de estilos, a justaposição, as mudanças de gêneros, tons e espírito de combate".

Efetivamente, nos anos 1960, surgem obras de grande criatividade e experimentação poética, como Rayuela (1963), de Julio Cortázar (1914-1984), cujo sucesso demonstrou a existência de um espaço de leitura diferente no circuito de bens culturais, um leitor, geralmente muito jovem, preparado para absorver a inovação estética aliada à reflexão metafísica. Outros destaques de criatividade na narrativa argentina dessa época são encontrados nas obras de Rodolfo Walsh (1927-1977), criador de um gênero inovador ${ }^{13}$ que aproxima a linguagem jornalística e a crônica política da ficção, como em Operación masacre (1957) e ¿Quién mató a Rosendo? (1969); ou nos romances de Manuel Puig (1932-1990), que se vale da

11 Donald L. Shaw, Ricardo-Gutiérrez Mouat, Roberto González Echeverría, acunharam o termo pós-boom.

12 A esse respeito, ver: Fornet (2005); Gutiérrez (2015); Laddaga (2007); Ludmer (2010); Montaldo (2014); Olmos (2011); Piglia (1986; 2001; 2004); Richard (1989; 1990; 1991).

13 O que mais tarde denominar-se-ia como non-fiction novel, ou reportagens organizadas literariamente. Segundo Ricardo Piglia (2013), a narrativa de Walsh é caraterizada pela capacidade de contar a história de maneira elíptica: brevidade, rapidez, quebra da temporalidade, ou seja, criar a história a partir de situações mínimas, cenas fugazes, linhas de diálogo, sem desenvolvimento lineal no sentido da narrativa tradicional. "[...] a história avança em rajadas, com grandes cortes e escansões, em flashes de ação, instantâneos. Nesse sentido, as narrativas de Walsh estão ligadas às pequenas parábolas, às alegorias e às formas breves típicas da prosa de Kafka, Borges ou Brecht (Piglia, 2013, p. 1). 
"[...] experimentação narrativa (a partir da utilização de técnicas cinematográficas como a montagem, o deslocamento, a livre associação de ideias) e o uso de formatos e estereótipos provenientes de gêneros considerados "menores", tais como o folhetim, ou a telenovela" (Jozef, 1999, [s.f.]), inovações presentes em suas obras mais destacadas: La traición de Rita Hayworth (1968), Boquitas pintadas (1969) e El beso de la mujer araña (1976).

A partir da apropriação e da reelaboração de materiais discursivos heterogêneos (literários e não literários), assiste-se ao surgimento de formas totalmente novas de narrar e vincular a história, no duplo sentido do termo, à ficção, "[...] efetuando rupturas com o cânone estabelecido, se aproveitado precisamente dos gêneros menores para renovar a literatura, tornandose, posteriormente, canônicos, como nas obras de Manuel Puig, por exemplo" (Gutiérrez, 2015, p. 98). É, portanto, um imaginário híbrido que deriva de diversas tradições culturais: das lutas locais transformadas pela transmissão oral em mitos e lendas (realismo mágico) até a multiplicidade de elementos da história e da cultura de massa, permitindo a reestruturação e a transformação estética e temática da literatura latinoamericana posterior aos anos 1960.

$\mathrm{Na}$ Argentina, na década de 1970, “[...] se realizam os primeiros mergulhos num novo tipo de criação, se definem tendências e estilos, se gestam os agrupamentos literários iniciais" (Cárcamo, 1990, p. 240). Os escritores da chamada geração de $70^{14}$ alguns apenas conhecidos nos anos 1960: Luisa Valenzuela (1938), Liliana Heker (1943) ou Ricardo Piglia (1941-2017), por exemplo - conhecem a tradição literária argentina e, o que é mais importante, sentem-se herdeiros de uma tradição que merece ser inventada:

Cada autor elabora um imaginário de literatura argentina, formula seus próprios recortes, para poder dessa maneira, situar a sua obra. Assim como a história não é mais concebida em termos de totalidade e de absoluto, a história literária nacional não é já considerada um processo contínuo, mas o espaço textual que se significa na articulação particular que cada escritor é capaz de realizar na sua própria escritura (Cárcamo, 1990, p. 242-243).
Os novos narradores dos anos 1970 demonstraram uma vontade de síntese visível na genealogia literária que cada um deles declara e que não é a mesma em todos os casos. De acordo com Jorge Volpi (2009), boa parte dos escritores nascidos a partir de 1960, e com livros publicados nos últimos anos, podem manter a América Latina como assunto de suas obras, mas sem a carga ideológica militante e utópica da década de 1960: "Testemunhas do esfacelamento do socialismo real e do descrédito das utopias, e cada vez mais céticos diante do político, esses autores parecem ter-se desprendido por fim de qualquer constrangimento nacional" (Volpi, 2009, p. 168). Em consequência disso, vinculam seu ceticismo e pouco engajamento político a um "orgulhoso desencanto". Por isso não precisam legitimar a tradição anterior (o boom) nem aspiram a ser portavozes da América Latina, preferem afrontar a realidade latino-americana (problemas e histórias) com naturalidade, sem o tom combatente de seus antecessores, sem esperanças nem compromisso político.

Por outro lado, um setor da crítica literária latinoamericana definirá as novas tendências como o pós-

\footnotetext{
$14 \quad$ Autores argentinos que publicaram suas primeiras obras na metade dos anos 1960 ou durante a década de 1970, entre outros: Alicia Steimberg (1933-2012), Liliana Heker (1943), Ricardo Piglia (1941-2017), Diego Angelino (1944), Jorge Asís (1946), May Lorenzo Alcalá (1946-2011), Jorge Manzur (1949-2015), Blas Matamoro (1942), Leonardo Moledo (1947-2014), Pacho O’Donnell (1941).
} 
boom da narrativa hispanoamericana, especialmente os continuadores do realismo mágico, circunscrevendo $\mathrm{o}$ termo a certo tipo de romances que adquiriram destaque graças ao mercado editorial dos anos 1980. Outros aspectos fundamentais a destacar da nova geração de narradores: a atualização de temáticas universais, a revisitação do passado, a hibridização do popular com o urbano, o cepticismo ideológico e a ironia crítica, uma literatura sem pretensões regionais, nacionais ou universais (Mejía Rivera, 2002; Fornet, 2005). Alguns romances - Días y noches de amor y de guerra (1978), de Eduardo Galeano (1940-2015); De amor y de sombra (1984), da escritora chilena Isabel Allende (1942); Ardiente paciencia (1985), de Antonio Skármeta (1940); La última canción de Manuel Sendero (1982), de Ariel Dorfman (1942); El color que el infierno me escondiera (1981), do uruguaio Carlos Martínez Moreno (1917-1986) - dão mostra da diversidade das formas narrativas do pósboom, onde também se aborda, em algumas dessas obras, a experiência traumática das ditaduras, a violência e o exílio latino-americano do período. É, portanto, um imaginário híbrido derivado de diversas tradições culturais: das lutas locais transformadas pela transmissão oral em mitos e lendas (realismo mágico) até a multiplicidade de elementos da história e da cultura de massa, permitindo a reestruturação e a transformação estética e temática da literatura da América Latina posterior aos anos 1960.

\section{Novas derivas estéticas}

$\mathrm{Na}$ literatura latino-americana mais recente, publicada a partir da década de 2000, emergem novos cenários narrativos, onde predominam a problematização crítica aliada à experimentação estética. As obras se destacam pelo hibridismo sem fronteiras demarcadas com outros gêneros, presentes também no nomadismo linguístico e transcultural, nas referências transversais às identidades e às culturas locais na conexão com o urbano, como se pode observar nas transcrições de Tré la tré María (2006), de Jorge Montesino (1962), a partir de sua herança paraguaia, e nos ciclos que se deslocam no portunhol de Fabián Severo (1981), em Viralata (2015), ou no "portunhol selvagem" de Douglas Diegues (1965), em Dá Gusto Andar Desnudo por Estas Selvas (2003), por exemplo. Outros cenários a serem destacados são caracterizados pela fragmentação do eu, representada, às vezes, pela sintaxe fraturada que traduz a dissolução interior, como pode ser visto em Bonsái (2006) e em La vida privada de los árboles (2007), de Alejandro Zambra, ou em Lecciones para una libre muerta (2005), de Mario Bellatin, onde a linguagem tenta explorar a radicalização das propostas experimentais neovanguardistas na relação da literatura e do homem com as tecnologias virtuais. ${ }^{15}$

Mas que elementos caracterizariam a narrativa atual da América Latina? Três palavras-chave a definiriam: inovação, hibridismo e inespecificidade. A inovação leva a superar as fronteiras artificiais dos gêneros literários, produzindo obras que não são facilmente circunscritas em definições fechadas de gênero, forçando a criação de categorias alternativas (romance-ensaio, relato-poema, biografia-diário, romance-diário, autoficção, entre outras), formas híbridas, que parecem querer sair de seus próprios limites além das margens da literatura. Como Ana Cecilia Olmos afirma (2011, p. 11-12), trata-se de escrituras que

[...] impulsionam a literatura em direção de uma deriva estética que desestabiliza as convenções, não para propor outras formas que acabem igualmente esclerosadas na

15 Gaitán Bayona (2014); Monroy Zuluaga (2014); Oliver (2015); Hernandez O. (2015); Conde de Boeck (2016); Vigna (2016), abordam diversos aspectos a respeito do cruzamento de línguas e fronteiras na literatura latino-americana contemporânea. 
proteção de seus limites, senão para levar a literatura para além do limite, empurrá-la permanentemente para o abismo que se abre quando se renuncia à tranquilidade das linguagens ordenadas e as certezas de seus fundamentos.

Nas obras de alguns escritores latino-americanos de hoje César Aira (1949) ${ }^{16}$, Roberto Bolaños (1953-2003), Héctor Abad Faciolince (1958), Elvio Gandolfo (1947), Sergio Pitol (1933), William Ospina (1954), Alejandro Zambra (1975), Jeremías Gamboa (1975), Juan Gabriel Vásquez (1973), Leonardo Padura (1955), Fernando Vallejo (1942), Alberto Manguel (1948), Alan Pauls (1959), Pablo de Santis (1963), Santiago Gamboa (1965), Mario Bellatin (1960), Silvia Molloy (1938), Edgardo Cozarinsky (1939), Mario Levrero (1940-2004), Martín Kohan (1967), Jorge Volpi (1968), entre outros autores ${ }^{17}$ é possível constatar a presença de textos que se situam na fronteira entre o ficcional e $o$ documental, experimentando permanentemente os limites dos gêneros, diante da feição digressiva e fragmentaria, o que dificulta ser classificados na categoria tradicional da ficção por desestabilizar o estatuto que separa o ficcional do documental. Trata-se, por tanto, de uma geração comprometida com a realização de estéticas inovadoras, explorando formas livres a partir de rupturas temáticas e estéticas, hibridismos, experimentação e intertextualidade.

\section{Segundo Rafael Gutiérrez} (2015), outros aspectos a destacar nas formas híbridas de alguns desses autores seriam a autoconsciência narrativa e a discussão do próprio processo criativo no interior das obras, que se apresentam como elementos ainda importantes para essas formas híbridas atuais, embora pareça que elas se colocam em um espaço diferente daquele característico dos anos 1980 e 1990, especialmente pela procura por produzir efeitos de realidade nos textos:
Se as obras metaficcionais procuravam evidenciar $\mathrm{o}$ caráter ficcional da realidade e da verdade enquanto construção narrativa, pelo contrário, nas formas híbridas recentes, se observa um apelo por produzir efeitos de realidade na ficção. A mistura de gêneros ficcionais e documentais, a inclusão de documentos e imagens de arquivo, o jogo permanente com a identidade real do autor, são algumas das estratégias usadas pelos textos para produzir estes efeitos de realidade (Gutiérrez, 2015, p. 95-96).

É possível observar, entretanto, que as características anteriormente mencionadas também aproximam a análise de questões relativas à problematização do próprio conceitodeficção, da enunciação discursiva e das maneiras específicas em que esses textos híbridos as desestabilizam. São interlocuções de caráter híbrido, no cruzamento de fronteiras, com presença de diversos gêneros: microficções, microbiografia, autobiografia,

16 É importante destacar a prolífica produção literária de César Aira com mais de 70 romances e relatos publicados de 1975 a 2015; galardoado em 2016 com o Prêmio Ibero-americano de Narrativa Manuel Rojas.

17 Uma série de obras ilustram a narrativa dos autores mencionados: Embalse (1992) e Cumpleaños (2000), El mármol (2011), de César Aira; La literatura nazi en América (1996), Los detectives salvajes (1998) e 2666 (2004), de Roberto Bolaños; Basura (2000), El olvido que seremos (2006), Traiciones de la memoria (2009), de Héctor Abad Faciolince; Ómnibus (2006), de Elvio Gandolfo; El mago de Viena (2005), de Sergio Pitol; El año del verano que nunca llegó (2015), de William Ospina; Bonsái (2006), La vida privada de los árboles (2007), Formas de volver a casa (2011), de Alejandro Zambra; Contarlo todo (2013), de Jeremías Gamboa; Historia secreta de Costaguana (2007), El ruido de las cosas al caer (2013), de Juan Gabriel Vásquez; La novela de mi vida (2002); El hombre que amaba los perros (2009); Herejes (2013), de Leonardo Padura; La virgen de los sicarios (1994), de Fernando Vallejo; Todos los hombres son mentirosos (2008), de Alberto Manguel; Historia del llanto (2007), de Alan Pauls; El enigma de París (2007), de Pablo de Santis; Plegarias nocturnas (2012), de Santiago Gamboa; Salón de belleza (1994), Lecciones para una libre muerta (2005), de Mario Bellatin; El común olvido (2002), Desarticulaciones (2010), Vivir entre lenguas (2016), de Sylvia Molloy; Lejos de dónde (2009), de Edgardo Cozarinsky; La novela luminosa (2008), de Mario Levrero; Los cautivos. El exilio de Echeverría (2000), Ciencias morales (2007), de Martín Kohan; En busca de Klingsor (1999), Examen de mi padre (2016), Una novela criminal (2018), de Jorge Volpi. 
autoficção, romance-diário, memórias, diário íntimo, ou seja, os denominados gêneros "menores", que ao participarem das novas formas híbridas deixam de ser secundários, tornando-se centrais na renovação literária.

Em contrapartida, é encontrada uma literatura que parece haver incorporado em sua linguagem e em suas funções uma relação com outros discursos e suportes em queoliterárioédesconstruído ou posto em questão. "A articulação dos textos com e-mails, blogs, fotografias, discursos antropológicos, entre outras variantes $[. .$.$] cifra nessa$ heterogeneidade uma vontade de imbricar as práticas literárias na convivência com a experiência contemporânea" (Garramuño, 2014, p. 35-36). Nesse tipo de obras, também está presente a ideia de uma literatura que se figura como parte do mundo e não como esfera independente e autônoma, senão "pósautônoma", que parece propor para si funções extrínsecas ao próprio campo disciplinar. De acordo com Josefina Ludmer (2007, p. 1), as literaturas pósautônomas,

[...] instalam-se localmente em uma realidade cotidiana para 'fabricar um presente' e esse é precisamente seu sentido [...] Muitas escrituras do presente atravessam a fron- teira da literatura (os parâmetros que definem o que é literatura) e ficam dentro e fora, como em posição diaspórica: fora, mas presas em seu interior. Como se estivessem 'em êxodo’. Seguem aparecendo como literatura e tem o formato livro [...] se incluem em algum gênero literário como o 'romance', e se reconhecem e definem a si mesmas como literatura [...] mas não se pode lê-las com critérios ou categorias literárias [...] são e não são literatura ao mesmo tempo, são ficção e realidade. Representariam a literatura no fim do ciclo da autonomia literária, na época das empresas transnacionais do livro ou das oficinas do livro nas grandes redes de jornais e rádios, televisão e outros meios. Esse fim de ciclo implica novas condições de produção e circulação do livro que modificam os modos de ler. Poderíamos chamá-las de escrituras ou literaturas pós-autônomas.

No conjunto, as obras híbridas apresentam alguns traços estilísticos a destacar: podem ser consideradas "formas breves", muito embora nem todas sejam necessariamente breves, são frágeis ou vulneráveis em algum sentido, “[...] o que as define não é tanto sua brevidade, mas o fato delas não chegarem a articular-se num lugar específico, a sustentar-se numa identidade" (Garramuño,
2014, p. 13-14). Algumas dessas obras são narradas na primeira pessoa, com tendência à concisão e à eliminação dos detalhes, das redundâncias; são relatos fragmentados, diretos, com frases curtas, apresentam saltos temporais e espaciais e/ou tramas paralelas no presente como imagens cinematográficas, minimalismo extremo, influência da multimídia e da performance ${ }^{18}$.

Um ponto em comum nesse tipo de obras é uma conjunção de formas, procedimentos, processos e mecanismos criativos semelhantes às instalações das produções artísticas contemporâneas, operando com o múltiplo, o heterogêneo e o disperso. Algumas se sustentam numa exposição da intimidade, parecendo encontrar no afeto o lugar. Outras se caracterizam também por serem "narrativas do eu", em que o privado emerge de maneira reiterada fazendo visível a experiência íntima, o segredo, a confissão, o que explora, assim, os limites entre literatura e vida (Giordano, 2008, 2017; Souza, 2017). Para Graciela Montaldo (2014),

[...] tudo o que se conta parece mais comunicável quando se faz na primeira pessoa, incluso o que se quer dizer do outro; incluso o que não pertence a ninguém; incluso

18 Brijaldo Olarte (2014) aponta algumas das possibilidades que a escrita adquire ao adotar integralmente seu caráter performático. 
aquilo que se imagina. Por isso, posso dizer que se há algo novo na produção estética mais recente se trata de um pacto entre autores e leitores segundo o qual o que se escreve ou lê na primeira pessoa - que pode ser lido autobiograficamente ou não - recebe, sob a forma da primeira pessoa, uma atenção especial, de algum modo se faz verosímil uma situação, como se nosso presente se tivesse instalado na primeira pessoa com certa comodidade de enunciação, e registrara nessa língua já bastante convencional da intimidade ou da confissão uma multiplicidade de formas de interpelação (p. 175-176) .

De acordo com Montaldo (2014), na atualidade existe um processo de globalização na arte que determina direta ou indiretamente - as novas tendências e estilos, e define as práticas culturais contemporâneas, seguindo um sistema de produção de obras cada vez mais uniformes, nas quais os procedimentos de criação formam parte de um processo de serialização (Richard, 2004) mas, cada obra deve mostrar sua singularidade, recorrendo à primeira pessoa, o que significaria a "institucionalização da primeira pessoa": "A produção da intimidade, da subjetividade, do privado, do segredo, não é alheia a essa serialização que, como procedimento, é recorrente na escrita e nas artes em geral, e muito mais nas mais invasivas práticas comunicacionais: a televisão, os jornais e revistas" (Montaldo, 2014, p. 178). Assim, a proliferação da primeira pessoa, na forma autobiográfica, ${ }^{19}$ explicaria o "[...] neo-individualismo capitalista que consagra o pessoal em detrimento do coletivo mediante a espetacularização do íntimo" (Richard, 2010, p. 72).

Pode-se dizer, então, que a produção literária contemporânea se encontra estreitamente vinculada às instituições culturais, quase todas, de uma forma ou de outra, ligadas ao mercado, estabelecendo assim um sistema de controle da criação artística, que está inserido na rede institucional, embora em alguns casos (em produções de vanguarda, por exemplo) tente sobreviver às imposições do mercado numa relação tensa com as instituições e as formas convencionais de circulação (Rancière, 2005). Portanto, podemos ver as produções de vanguarda ${ }^{20}$ como uma resposta política específica ao neoliberalismo e à hegemonia cultural implícita no próprio sistema. A vanguarda, para Ricardo Piglia (2007, p.7-8),

[...] faz ver o que as ideias dominantes negam e pretende atacar os centros de poder cultural e alterar hierarquias e modos de significar. Utiliza as manobras de fraternidade e terror dos grupos dos que Sartre falava contra a falsa ilusão do acordo e o consenso, opõe a provocação à ordem, opõe seita à maioria, tem uma política determinada, ao mesmo tempo escandalosa e hermética, contra o falso equilíbrio natural do mercado e a circulação de bens culturais. A vanguarda artística é claramente decifrada como uma prática antiliberal, como uma versão conspiratória da política e da arte, como um complot que experimenta novas formas de sociabilidade, que se infiltra nas instituições existentes e tende a destruí-las e a criar redes e formas alternativas. Obviamente, toda a política de vanguarda tende a opor-se ao gosto da maioria e ao conhecimento submetido do consenso. A vanguarda levanta imediatamente a necessidade de construir um complot para quebrar o cânone e negar a tradição estabelecida e impor outra hierarquia e outros valores.

$\begin{array}{lrr}\text { Em } & \text { conformidade } & \text { com } \\ \text { essa } & \text { perspectiva, } & \text { a }\end{array}$

\footnotetext{
19 Pesquisadores como Saavedra Galindo ( 2017); Escobar Vera (2017); Dominguez Torres (2017); Diaconu (2017); Musitano (2017), examina de perto a "autoficção" e seu papel na literatura latino-americana atual.

20 Vanguarda entendida aqui não apenas como uma prática artística, mas como uma maneira de ler e reformular tradições, como uma atitude combativa em relação a valores institucionalizados, hierarquias literárias, e lugares comuns (Piglia, 1986).
} 
"institucionalização da primeira pessoa" emerge como tensão no mundo administrado, mas uma tensão que responde a uma nova forma de disciplinamento expressada também nas práticas culturais contemporâneas. Ao analisar a relação da estética e da política contemporânea, Jacques Rancière (2005a) as considera formas não correlativas de representação, não há diálogo nem aliança entre elas, mas confrontação. Enfrentam-se de diversas maneiras e por meio de práticas diferentes, gerando conflitos e desacordos. "A política cria conflito. A estética abre modos de ver, saca os problemas da tradição e os confronta com o sentido comum [...] a política é a prática na que as palavras não coincidem com as coisas. Exatamente como na literatura" (Montaldo, 2014, p. 179).

Muitas das obras e instituições trabalham juntas, geralmente na mesma direção. No entanto, alguns artistas e escritores estabelecem formas particulares de criação para continuar produzindo suas obras num sentido diferente ao instituído pelo mercado e pelas instituições. Eles usam a estética como instrumento de 'desacordo' ${ }^{21}$ dentro da própria obra, “[...] e em suas mãos a estética ataca as instituições ao mesmo tempo que mantém o lugar hoje central destas na produção estética. A estética está aí concebida não como a raiz da arte, mas como um atributo e uma estratégia" (Montaldo, 2014, p. 179).

Em La novela luminosa (2008) de Mario Levrero, é possível encontrar um exemplo do tipo de estratégia artística em que o autor coloca o eu como instrumento de pesquisa: a trama se estabelece na interrelação entre arte, instituições culturais e indústria cultural. Levrero explora o vínculo da literatura e o dinheiro, o patrocínio e a criatividade, ao contar num romancediário sua própria experiência como bolsista da Fundação Guggenheim, instituição que lhe concedeu uma bolsa para escrever uma obra literária: $L a$ novela luminosa, publicada um ano após sua morte. Das mais de quatrocentas páginas da obra, só as cem últimas correspondem ao romance, o restante é uma espécie de diário íntimo ("o diário da bolsa") onde o autor registra sua relação conflituosa com a escrita, o corpo, o dinheiro e com a Fundação Guggenheim: "[...] Uma das primeiras coisas que fiz com a primeira metade do dinheiro da concessão foi comprar poltronas [...]. Fui ao caixa eletrônico e retirei duzentos dólares do $\mathrm{Sr}$. Guggenheim [...]. Já tenho as poltronas, os estantes, e espero ter o ar condicionado" (Levrero, 2008, p. 24, 181, 302). Assim, Levrero faz do leitor o seu confidente, ao lhe revelar as experiências "luminosas" de sua vida: o medo da morte, o fracasso do amor, as dificuldades da velhice, as doenças, as trivialidades de seu dia a dia e, também, a impossibilidade de escrever um romance para o qual foi pago.

Dessa forma, o texto é uma espécie de 'confissão' das condições de trabalho daquilo que não pode necessariamente ser considerado um 'trabalho', ou de como a literatura passa a ser um trabalho. $\mathrm{O}$ narrador do texto na primeira pessoa revela como são as condições de trabalho para o escritor contemporâneo, questiona também a prática literária, os gêneros literários e o lugar da autoridade, a escrita e as instituições. Como diz Montaldo (2014, p. 181):

Podemos ler o "diário" como um experimento que consiste em refletir sobre a nova institucionalização internacional da cultura e seus efeitos nas obras literárias. O romance

$21 \quad$ Segundo Rancière (1996), o desacordo sempre é irreconciliável, é uma forma especial de interlocução. "Por desacordo se entenderá um tipo determinado de situação de fala: aquela na que um dos interlocutores entende e ao mesmo tempo não entende o que diz o outro. O desacordo não é o conflito entre quem diz branco e quem diz preto. É o existente entre quem diz branco e quem diz branco, mas não entende o mesmo, ou não entende que o outro diz o mesmo com o nome da brancura" (Rancière, 1996, p. 3). Nesse sentido, a política sempre é um desacordo, um momento de conflito. 
de Levrero é um raro objeto de vanguarda que mostra novos vínculos entre escrita, política, mercado e autoridade $[\ldots]$ também faz com que todos esses vínculos se mostrem em sua face mais problemática.

Em La Novela Luminosa podem-se detectar, igualmente, duas postulações assinaladas por Ludmer (2007, p. 2) sobre as literaturas pós-autônomas: "O primeiro é que todo o cultural (e literário) é econômico e todo o econômico é cultural (e literário). O segundo postulado dessas escrituras seria que a realidade (se pensada a partir os meios que a constituiriam constantemente) é ficção e que a ficção é a realidade". Isso ocorre porque tais escrituras reformulam a categoria da realidade, não se podem ler apenas como obras "realistas" mesmo com referências que aludem ao mundo real, nem como obras "ficcionais" porque adotam gêneros literários vinculados com a "realidade": autobiografia, testemunho, crônica, reportagem jornalística, diário íntimo, entre outras formas híbridas que colocam a literatura nas duas fronteiras para fabricar o presente com a realidade cotidiana e construir assim as ficções do presente.

\section{Textos migrantes}

$\mathrm{Na}$ literatura mais recente, surgem também formas de narrar que já não se definem pela articulação romanesca tradicional de uma história. São textos que exibem uma série de técnicas inovadoras que, de certa forma, pela irreverência e pela alta experimentação, remetem ao espírito criativo das vanguardas dos anos 1920. Diferentemente do 'hibridismo formal', da mistura de linguagens ou da colagem tradicional realizadas no período do boom, aparecem implicados nesses textos mesclas aleatórias de fragmentos e de elementos heterogêneos. Vários tipos de especificidades - nacional, pessoal, genérica, literária são dissolvidos num número cada vez mais importante de textos migrantes, sem território fixo, que exibem uma intensa porosidade de fronteiras em diálogo multidisciplinar com diversas artes, problematizando dessa forma, o próprio espaço de criação literária e colocando em questão a ideia de pertencimento, especificidade e autonomia artística (Ludmer, 2010).

Florencia Garramuño (2014), ao refletir sobre as especificidades da linguagem artística, destaca uma série de obras literárias caras à arte e à estética contemporânea por desafiarem as propriedades e as espécies que as caracterizam. Trata-se de obras que não são necessariamente semelhantes em termos formais, difíceis de ser categorizadas e definidas pelo emprego de meios e formas diversas, "frutos estranhos" 22 , enquanto inespecíficos e fora de sua espécie, “[...] misturas e combinações inesperadas, saltos e fragmentos soltos, marcas e desenquadramentos de origem, de gêneros e disciplinas, parecem compartilhar um mesmo desconforto em face de qualquer definição específica ou categoria de pertencimento em que instalar-se" (Garramuño, 2014, p. 10-11).

O processo de composição desses "textos instalações" ou "frutos estranhos" se materializa na estruturação de um textoobjeto composto, como já dito, de fragmentos diversos que se incorporam ao espaço do livro enquanto materialidades heterogêneas que dão a ideia, não de uma colagem, mas de uma instalação cuja trama desconjuntada incorpora objetos diversos no espaço da escrita agora convertida em cenário ou 'puesta en escena'. Assim, num mesmo espaço narrativo emergem relatos entrecruzados com poemas, fotografias, fragmentos diversos, imagens, tal como sucede em Nove noites (2002), de Bernardo Carvalho (1960), El infarto del alma

22 Refere ao título de uma instalação do artista brasileiro Nuno Ramos, exposta no MAM do Rio de Janeiro de setembro a dezembro de 2010. 
(1994), de Diamela Eltit (1949), Bénedicte vê o mar, de Laura Erber (1979), ou em Examen de mi padre (2016), de Jorge Volpi, por exemplo. Os autores constroem as histórias com referências explícitas a outros dispositivos ou meios, em constante trânsito e expansão das linguagens artísticas para além de suas próprias especificidades numa literatura "fora de si", mas conectada com vários gêneros sem pertencer a nenhum: romances que seriam 'textos-instalações'; poemas que recolocam em "passos de prosa" a relação poesiaemoções-afetos; fragmentos soltos que ao entrecruzar mundos de referência, desafiam a propriedade e a especificidade da arte. Algumas dessas obras se equilibram em suportes precários, outras apresentam o nomadismo intenso e o movimento constante de espaços, lugares, subjetividades, afetos, operações que se repetem vezes seguidas. "Mas todas elas revelam, em seu conjunto - para além das diferenças formais entre elas -, um modo de estar sempre fora de si, fora de um lugar ou de uma categoria próprios, únicos, fechados, pristinos ou contidos" (Garramuño, 2014, p. 12).
Ao fazer ruir a noção de pertencimento do lugar de origem, as novas formas experimentam as territorialidades comoum campo movediço em transformação. As estéticas migrantes estabelecem diálogos temporais e/ou espaciais em constante deslocamento. A literatura em movimento, determinada pela operacionalização de categorias que se renovam com as geopolíticas das diásporas, dos fluxos migratórios em que se manifesta o nomadismo cultural, das configurações de novos gêneros e das subjetividades em trânsito, leva à reflexão sobre o fenômeno literário e artístico produzido no deslocamento de textos, espaços, identidades, linguagens e formas simbólicas ${ }^{23}$.

Em Lejos de donde (2009) ${ }^{24}$, romance de Edgardo Cozarinsky (1939), a sensação de desarraigamento vincula o emocional e o onde, fazendo ruir toda a noção de pertencimento de lugar de origem ao construir uma história de migrações de ida e volta que encontra em seu título $^{25}$ um modo produtivo de apontar para essa fuga constante das molduras e dos lugares de pertencimento:
Se por um lado o movimento de vaivém que imprime à história o percurso de migrações e a problematização das identidades aponta para essa noção de não pertencimento, por outro, a continuidade entre ficção e realidade, com os dados de lugares e episódios e a ilação de fragmentos da história da Segunda Guerra Mundial na Europa, e o modo como seus estilhaços e ecos ressoam e ancoram na Argentina contribuem para fazer desse vaivém do não pertencimento uma noção ainda mais insistente (Garramuño, 2014, p.12-13).

No relato, os destinos nômades se multiplicam e as identidades falsas se sobrepõem, os personagens habitam espaços íntimos e periféricos, zonas transicionais nas quais nada fica perto nem longe. Cozarinsky arma as histórias " [...] a partir de relatos, experiências de amigos, conhecidos circunstanciais ou fatos históricos. Trata-se de restos de histórias herdadas, cuja origem o escritor nem sempre lembra com precisão" (Beccacece, 2009, [s.p.]). Assim, o documental e o ficcional se mesclam e comunicam indistintamente, lançando a especificidade da literatura para uma "[...] zona em que as elucubrações

23 Reflexões sobre estéticas migrantes podem ser encontradas em: Augé (1994); Bernd (2010); Bhabha (2003); Braidotti (2000); Ferman (1997); García Canclini (1993; 2010); Margato (2008); Palmero (2010); Richard (1991).

24 Recebeu o Prêmio da Academia das Letras Argentinas em 2011, como a melhor obra narrativa de 2008 a 2010.

25 O título corresponde a uma cena de El rufián moldavo (2004), outra obra de Cozarinsky, na qual o deslocamento e a indistinção entre realidade e ficção se entrecruzam "[...] fazendo com que o texto apareça como a sombra de uma realidade que não consegue iluminar-se por si mesma" (Garramuño, 2014, p. 22). 
sobre ela valem mais pelo que dizem com respeito a questões existenciais ou conflitos sociais que habitam esse outro espaço, com o qual se elabora essa contiguidade, do que por aquilo que elas podem dizer a respeito do texto enquanto tal, em sua especificidade" (Garramuño, 2014, p. 21-22).

No entrelaçamento de meios, gêneros, suportes e linguagens, e nos vínculos multidisciplinares, é possível observar uma saída da especificidade do meio, do próprio, da propriedade de cada uma das textualidades contemporâneas. A aposta no inespecífico seria uma maneira de elaborar uma linguagem do comum que propiciasse modos diversos de não pertencimento a uma ideia de arte como específica.

\section{Considerações finais}

A partir das considerações precedentes, num recorte parcial e estudo inicial, foi possível observar algumas das transformações do estatuto literário na narrativa latinoamericana contemporânea, do período do boom ao presente, destacando aspectos relevantes quanto à sua inovação temática e formal, permitindo definir cenários e explorar, por isso mesmo, outras formas de pensar e de analisar o potencial crítico da arte e da literatura do presente. Como visto, é uma literatura que parece ter incorporado em sua linguagem uma relação complexa com outros discursos, disciplinas e práticas artísticas. Se a partir da década de 1960 os esforços apontavam tanto para a reabilitação entre arte e vida quanto para a expansão das disciplinas artísticas, forçando os limites, o que se verifica nos últimos anos é a radicalização dessa tendência, cuja força reside no questionamento da ideia de especificidade a sustentar categorias, ordens e espaços fechados (Garramuño, 2014).

Por outro lado, a noção de ficção instituída a partir do século XIX é substancialmente alterada. Atualmente, a narrativa canônica com fronteiras bem delimitadas entre "realidade histórica" (o histórico como real) e "ficção" (o literário como fábula, mito, alegoria ou pura subjetividade) tem sido modificada para dar passo, segundo Ludmer (2010), a uma espécie de "realidadeficção" que traduz assim a realidade cotidiana do presente na era da mídia e da imaginação pública. Hoje as identidades literárias e os campos relativamente autônomos do político, do económico, do real, são apagados, para contêlos e fundi-los em sua própria interioridade, num processo de perda (ou perda aparente?), da autonomia literária e do poder crítico que a autonomia atribuiu à literatura como política própria, específica (Ludmer, 2007).

A produção literária das últimas décadas do século XX e início do século XXI é caracterizada pela pluralidade de autores, assuntos, gêneros, formas, estilos, culturas diversas, sem tendências estéticas nem escolas definidas. Essa tendência, se assim pode ser denominada, permite estabelecer um panorama de contrastes para abordar com novas aproximações críticas, os vários micromundos que constituem uma geografia plural e mutante. Um território onde o romance parece ser o gênero preferido dos autores e leitores, mas variadas misturas genéricas experimentais disputam com a linha tradicional em uma aposta pela liberdade de expressões estéticas que incorpora com naturalidade a tradição literária universal, para fazer jus ao postulado borgiano.

Após as transformações da narrativa mundial dos anos 1980 , a literatura latino-americana já não se define, necessariamente, pelas tradições regionais nem a linguagem local, deixando de legitimar as representações do realismo mágico, do real maravilhoso, do realismo fantástico, do tropicalismo, da barbárie, ou do romance de ditadores. Agora pretende simbolizar qualquer espaço, ser metonímia do mundo, advoga assim pela liberdade conceitual 
e criativa dos autores, expressa em uma narrativa eclética e multifacetada, heterogênea, intertextual, com hibridização de gêneros e estruturas (Volpi, 2009).

Dentro desse universo diverso, destacam-se algumas vertentes da narrativa atual, entre outras: as "narrativas do eu" presentes no romance biográfico ou autobiográfico experimental; as múltiplas identidades abrindo possibilidades às diversidades de gênero onde o subjetivo se impõe ao social; a chamada "estética pop", com expressões mutantes, produto das migrações, dos encontros e cruzamentos que derivam em hibridismos, misturas, ecletismos, mestiçagens; a influência do audiovisual e do cinematográfico nas interações da imagem e do texto na criação literária; a forte presença da narrativa realista no romance policial; a revisitação das histórias locais, em latitudes distantes e perspectivas oblíquas, com foco na política contemporânea para reinterpretar os efeitos dos conflitos do passado no presente, nas "narconovelas" (México), ou nos romances sobre 0 conflito armado, a guerrilha, o narcotráfico (Colômbia), ou as releituras sobre os efeitos das últimas ditaduras latinoamericanas (Brasil, Argentina, Chile) (Manrique Sabogal, 2008).
Os novos narradores escolhem o caminho oposto ao da tradição do boom que teve compromisso ideológico com as lutas sociais e resistência às ditaduras militares dos anos 1960 e 1970. Agora, a literatura não precisa, necessariamente, cumprir uma função política e social, mas ter um valor intrínseco enquanto arte, também um compromisso ético diante dos acontecimentos do presente. Para tanto, descrevem mundos próximos e íntimos, fazendo do particular e singular, o universal. Transitam em múltiplas e diversas derivas numa aparente renuncia à criação de uma obra que expresse a complexidade do mundo contemporâneo na ficção, porém, noutras bifurcações, a hibridização genérica desemboca no jornalismo cultural e na nãoficção, localiza-se numa zona ambígua onde se entrecruzam o romance, a crônica e o ensaio, produzindo assim efeitos de ficção na "realidade".

A atual narrativa contemporânea da América Latina caracterizase por ser heterogênea, multicêntrica, diversa, inespecífica, híbrida, nômade, sem "pertencimento definido" nem afiliação a escolas ou a movimentos, sem apego a dogmas e a tendências preestabelecidas, sem rótulos válidos para defini-la, sem forças de aglutinação, com um considerável número de autores publicando em diferentes espaços e exercendo funções diversas, quase todas ligadas à palavra: tradutor, professor, jornalista, publicitário, cineasta, que permite a expansão da literatura em outras áreas, possibilitando, no entrecruzar transdisciplinar, novos olhares e leituras críticas.

Uma pergunta norteadora que pode ser considerada central para o desenvolvimento futuro deste estudo: como ler a literatura latino-americana atual à luz das novas tendências e estilos? Outras perguntas se desprendem da anterior como possíveis diretrizes de exploração: como se configuram as novas tendências e estilos da narrativa latino-americana contemporânea? Como opera seu estatuto ficcional? Em que contexto surgem? Quais modelos e técnicas narrativas se impõem? Como é narrada a tensão entre o cotidiano, o imaginário, as histórias locais e os modelos narrativos globalizados? Como os processos de hibridização da estrutura textual se apresentam como expressão de novos imaginários, práticas e produções que emergem dos novos entrelaçamentos $\mathrm{e}$ configurações discursivas? As textualidades contemporâneas com quais tradições culturais dialogam? Em suma, essas séries de questões direcionaram a pesquisa a novos territórios críticos que modificaram as formas de ler e interpretar a literatura latino-americana do presente. 


\section{Referências}

Aguilar, P. (verano 2013). Ni mágico ni maravilloso: realismo visceral y fantástico rioplatense en Llamadas telefónicas. Pasavento. Revista de Estudios Hispánicos. (vol. I, n. o 2), 299-309.

Augé, M. (1994). Não-lugares (introdução a uma antropologia da supermodernidade). (M. L. Pereira, trad.). Campinas: Papirus.

Beccacece, H. (2009). Sobre vidas oscuras y usurpadas. ADN cultura/La Nación. Recuperado el 10 de octubre de 2016, de http://www.lanacion.com.ar/1183006-sobre-vidas-oscuras-y-usurpadas

Brijaldo Olarte, G. (enero-junio de 2014). Interpretaciones íntimas sobre la escritura performativa. La Palabra, (24), 111-117.

Bhabha, H. K. (2003). O local da cultura. (M. Á. trad.). Belo Horizonte: Editora UFMG.

Braidotti, R. (2000). Sujetos nómades. Buenos Aires: Editorial Paidós.

Bueno, R. (1991). Escribir en Hispanoamérica. Ensayos sobre teoría y crítica literarias. Lima/Pittsburgh: Latinoamérica Editores.

Cárcamo, S. I. (1990). Posfácio. En: M. L. Alcalá. Nova narrativa argentina (p. 237-247). São Paulo: Iluminuras.

Collazos, O. Cortázar, J. Vargas LLosa, M. (1970). Literatura en la revolución y revolución en la literatura. México: Siglo XXI Editores.

Collazos, O. (1969). La encrucijada del lenguaje. Marcha. Montevideo, 30 de agosto (1460).

Cortázar, J. (2007). Rayuela. Edición de Andrés Amorós. 19. ed. Madrid: Editorial Cátedra.

Cortázar, J. (2011). O jogo da amarelinha. (F. de Castro Ferro, trad.). 16. ed. Rio de Janeiro: Civilização Brasileira.

Cortázar, J. (2016). 62/Modelo para armar. Buenos Aires: Alfaguara.

Cozarinsky, E. (2009). Lejos de donde. Buenos Aires: Tusquets.

Diaconu, D. (enero-junio de 2017). La autoficción: simulacro de teoría o desfiguraciones de un género. La Palabra, (30), 35-52.

Diegues, D. (2003). Dá Gusto Andar Desnudo por Estas Selvas. Curitiba: Travessa dos Editores. 
Domínguez Torres, M. A. (enero-junio de 2017). El espejo en La Rambla paralela (2002) de Fernando Vallejo. La Palabra, (30), 53-68.

Donoso, J. (1999). Historia personal del boom. Madrid: Alfaguara.

Eltit, D., y Errazuriz, P. (1994). El infarto del alma. Santiago de Chile: Francisco Zegers.

Escobar Vera, H. (enero-junio de 2017). Guiño, ambigüedad e incertidumbre: claves de lectura y efectos estéticos del pacto ambiguo. La Palabra, (30), 69-91.

Fornet, J. (2005). Nuevos paradigmas en la narrativa latinoamericana. Latin American Studies Center. Maryland: University of Maryland, College Park, n. 13, 1-52. Recuperado el 25 de octubre de 2016 de http://www.lasc.umd.edu/Publications/WorkingPapers/NewLASCSeries/wp13.pdf

Gaitán Bayona, J. L. (enero-junio de 2014). Metaficción y Escritura del desastre en Simone, de Eduardo Lalo. La Palabra, (24), 79-87.

Galindo, C. (1978). El boom en Latinoamérica. En: Glantz, M. La literatura II. México: Universidad Autónoma de México (pp.131-146).

García Canclini, N. (1993). Culturas Hibridas. Estrategias para entrar y salir de la modernidad. México: Editorial Grijalbo.

Garramuño, F. (2014). Frutos estranhos. Sobre a inespecificidade na estética contemporânea. Rio de Janeiro: Editora Rocco.

Giordano, A. (enero-junio de 2017). Ejercicios de supervivencia. La Palabra, (30), 277-286.

Giordano, A. (2008). El giro autobiográfico de la literatura argentina actual. Buenos Aires: Mansalva.

Giordano, A. (2010). Los límites de la literatura. Rosario: Cuadernos del Seminario. Centro de Estudios de Literatura Argentina.

Gutiérrez, R. (2015). Formas híbridas na literatura latino-americana contemporânea. Revista Landa, 3 , 94-115.

Gutiérrez-Mouat, R. (1983). José Donoso: impostura e impostación. La modelización Indica y carnavalesca en la producción literaria. Gaithersburg, Md: Hispamérica.

Harss, L. (2012). Los nuestros. Madrid: Alfaguara.

Hernández O., B. (julio-diciembre de 2015). Poéticas de la reescritura: Héctor Viel Temperley y Leónidas Lamborghini. La palabra, (27), 127-146. 
Horne, L. (2011). Literaturas reales. Transformaciones del realismo en la narrativa latinoamericana contemporánea. Rosario: Beatriz Viterbo.

Jozef, B (1999). Manuel Puig: las máscaras y los mitos en la noche tropical. Ciberletras: Revista de Crítica Literaria y de Cultura, 1. Recuperado el 30 de marzo de 2016 de http://www.lehman. cuny.edu/ciberletras/v1n1/ens_06.htm

Laddaga, R. (2006). Estéticas de la emergencia. La formación de otra cultura de las artes. Buenos Aires: Adriana Hidalgo.

Laddaga, R. (2007). Espectáculos de realidad. Ensayo sobre la narrativa latinoamericana de las últimas dos décadas. Rosario: Beatriz Viterbo.

Levrero, M. (2008). La novela luminosa. Barcelona: Mondadori.

Ludmer, J. (2007). Literaturas posautónomas. Ciberletras - Revista de crítica literaria y de cultura, 17. Recuperado el 16 de febrero de 2017 de http://www.lehman.cuny.edu/ciberletras/v17/ludmer. htm

Ludmer, J. (2010). Literaturas pós-autônomas. Sopro 20 (Panfleto político-cultural). Recuperado el 16 de febrero de 2017 de http://www.culturaebarbarie.org/sopro/n20.pdf

Ludmer, J. (2010). Aquí América Latina. Una especulación. Buenos Aires: Eterna Cadencia.

Manrique Sabogal, W. (2008). América Latina pasa página. ¿Hacia dónde va la literatura latinoamericana? El País/Babelía. Recuperado el 17 de octubre de 2017 de https://elpais.com/diario/2008/05/24/babelia/1211585953_850215.html?rel=mas

Mejía Rivera, O. (2002). La generación mutante: nuevos narradores colombianos. Colombia: Editorial Universidad de Caldas.

Molloy, S. (2010). Desarticulaciones. Buenos Aires: Eterna Cadencia.

Montaldo, G. (2014). La culpa de escribir. Cuadernos de Literatura, XVIII (35),173-187.

Monroy Zuluaga, L. (julio - diciembre de 2014). Entre el artista y el crítico: Basura de Héctor Abad Faciolince. La Palabra (25), 57-68.

Montesino, J. (2009). Tré la tré María (novelita-í). Córdoba: Babel Editorial.

Mora Valcárcel, C. (1985). Julio Cortázar. En: C. Mora Valcárcel. Historia de la literatura latinoamericana 3 (pp. 41-56). Madrid: Planeta Agostini. 
Musitano, J. (enero-junio de 2017). El problema del nombre. Los casos de Jorge Baron Biza y Julián Herbert. La Palabra, (30).

Oliver, F. (enero-junio de 2015). Mano de obra. El supermercado por dentro. La Palabra (26), 75-84.

Olmos, A. C. (2011). Transgredir o gênero: políticas da escritura na literatura hispano-americana atual. Revista Estudos de Literatura Brasileira Contemporânea, 38, 11-21.

Pérez Montañez, A. (2013). Vozes do exílio e suas manifestações nas narrativas de Julio Cortázar e Marta Traba. Londrina: Eduel, Editora da Universidade Estadual de Londrina.

Perus, F. (1983). Balance y perspectivas de la investigación literaria en América Latina (mimeo).

Instituto de Investigaciones sociales. Posgrado en Estudios Latinoamericanos. Facultad de Filosofía y Letras, UNAM, 1-18.

Piglia, R. (1986). Crítica y ficción. Barcelona: Anagrama.

Piglia, R. (2007). Teoría del complot. Buenos Aires: Mate.

Piglia, R. (2013). Dos observaciones sobre Rodolfo Walsh. ADN Cultural/ La Nación. Recuperado el 30 de abril de 2016 de http://www.lanacion.com.ar/1589001-dos-observaciones-sobre-rodolfo-walsh

Rama, A. (1982). Transculturación narrativa en América Latina. México: Siglo XXI Editores.

Rancière, J. (1996). El desacuerdo. Política y filosofia. Buenos Aires: Ediciones Nueva Visión.

Rancière, J. (2005a). A partilha do sensivel. (M. Costa Netto, trad.). São Paulo: EXO Experimental Org./ Ed. 34.

Rancière, J. (2005b). Política da arte. São Paulo S.A.: práticas estéticas, sociais e políticas em debate. Situação \# 3 - Estética e Política. Recuperado el 25 de octubre de 2016 de http://www.sescsp. org.br/sesc/images/upload/conferencias/206.rtf

Richard, N. (2004). Prólogo. En: T. Escobar. El arte fuera de si (pp. 9-15). Asunción: Museo del Barro.

Richard, N. (2010). Crítica de la memoria (1990-2010). Santiago: Ediciones Universidad Diego Portales.

Saavedra Galindo, A. (enero-junio de 2017). Los nombres de la realidad. Autoficción en Formas de volver a casa. La Palabra, (30), 93-106.

Souza, E. M. (enero-junio de 2017). Autoficção e sobrevivência. La Palabra, (30), 107-114. 
Schøllhammer, K. E. (2004). Prefácio. En: P. Vidal. A história em seus restos: Literatura e exílio no cone sul (pp. 13-15). São Paulo: AnnaBlume Editora.

Severo, F. (2015). Viralata. Montevideo: Rumbo Editorial.

Shaw, D. (2005). La nueva narrativa hispanoamericana. Boom, pós-boom, pós-modernismo. Madrid: Cátedra.

Smith, T. (2012). ¿Qué es el arte contemporáneo? Buenos Aires: Siglo XXI.

Vidal, P. (2004). A história em seus restos: Literatura e exílio no cone sul. São Paulo: AnnaBlume Editora.

Vigna, D. (julio-diciembre de 2016). Exhumación informática en el Archivo de Daniel Moyano. Una reflexión sobre soportes, materialidades y el devenir de originales y borradores. La Palabra, (29), 139-158.

Volpi, J. (2009). El insomnio de Bolivar. Cuatro consideraciones intempestivas sobre América Latina en el siglo XXI. Barcelona: Debate.

Walsh, R. (2008). Operación Masacre. Buenos Aires: Ediciones de La Flor.

Walsh, R. (1997). ¿Quién mató a Rosendo? Buenos Aires: Ediciones de La Flor.

Xavi, A. (2013). Aquellos años del boom. García Márquez, Mario Vargas Llosa y el grupo de amigos que lo cambiaron todo. Canadá: Editora RBA.

Zambra, A. (2016). Bonsái \& La vida privada de los árboles. Barcelona: Anagrama. 
